\title{
A Personal Review on 40 Years at the Kantonales Labor Zurich: Success - Failure - Conclusions
}

\author{
Koni Grob*§
}

\begin{abstract}
My career at the Kantonales Labor Zürich $(\mathrm{KLZH})$ started with the introduction of capillary gas chromatography (GC) and took me through an ideal curriculum: first the elaboration of a solid technical background, then a broad range of applications covering all stages from the development of smart and solid methods, understanding the background of a matter and searching for solutions and risk assessment, lobbying to get solutions implemented, sometimes even writing legislation. Selected milestones are described with how the subject came up, what we did and a critical review of the success we had. This gave ample opportunity to think about consumer protection, efficiency in control and performance of authorities. It was a highly motivating job, but sometimes also frustrating because of the weak position of the authorities in defending public interests against big industry. Authorities should be respected, which primarily means competence, strict implementation of relevant rules and insistence if necessary. Often this has little to do with the number or samples analyzed - on the contrary: high sample throughput often prevents us going into depth. In all, what the food safety authorities are capable of implementing is far from that promised to the consumers by legislation.
\end{abstract}

Keywords: Acrylamide · Biphenyl A diglycidyl ether (BADGE) · Food analysis · Gas chromatography

\section{Capillary Gas Chromatography}

On April 29, 1979, Dandeneau and Zerenner from Hewlett Packard (now Agilent) showed in a small lecture room at Hindelang (Germany) how they could bend fused silica capillaries for gas chromatography (GC) and even form a knot without breakage. This was spectacular for the small community working with glass capillary columns and helped pave the way for capillary GC. Unless specified otherwise, at that time GC automatically implied packed columns. Little more than 10 years later, unspecified GC automatically meant separation on capillary columns.

At the same meeting I gave a lecture on partial sample evaporation in the syringe needle during injection into a conventional split/splitless injector. It was our first work about the severe problems in GC injection: the volume was wrong, the composition of the sample reaching the column distorted and not reproducible unless needle handling was systematically controlled: the

${ }^{*}$ Correspondence: Dr. K. Grob

Kantonales Labor Zürich (Official Food Control Authority of the Canton of Zurich)

Fehrenstrasse 15, CH-8032 Zurich

Tel.: +41432447131

E-mail: koni@grob.org

\$The opinions expressed in this article are not neces-

sarily supported by the Kantonales Labor Zürich volatiles left completely, while high boiling components remained in the needle at variable proportions. We recommended 'hot needle' injection to achieve violent evaporation and nebulization, ${ }^{11]}$ whereas Hewlett Packard soon introduced the fast autosampler to suppress evaporation in the needle - for those owning an autosampler (our laboratory did not at that time).

However, 1979 was not the start of capillary GC in Zurich. Around 1961, in the cellar of his school house, few $100 \mathrm{~m}$ from the KLZH, my father (from 1969 supported by my mother) tried to identify the carcinogen(s) in cigarette smoke to develop effective filters and enable smoking all day long without a risk of lung cancer. This failed, but they succeeded in developing advanced capillary GC in terms of making (glass) capillary columns and splitless injection. ${ }^{[2]}$ The first commercial producer of capillary columns, Hansjürg Jäggi, was the technician at this school.

\section{GC Technology}

My GC career at the Kantonales Labor Zürich (KLZH) started in 1974 with a phone call: in hardly $5 \mathrm{~min}$ and without filling in forms I had a job for 2 months. Using two glass capillary columns from my parents, H. P. Neukom and I got an instrument running and characterized edible fats and oils by the composition of the fatty acid methyl esters. We also analyzed drinking water for contaminants, such as tetrachloroethylene, present in the main source of the ground water of Zürich at concentrations which were soon no longer tolerable even for wastewaters. This job became permanent, first for a single day per week (I was in the middle of my university studies), then $60 \%$. I used the spare time for my four sons, rebuilding a large house, supplying the kitchen from a large garden and cutting trees for heating, but also for writing books, teaching GC courses throughout the world as well as consulting for an instrument and a column manufacturer. I only started working full time for the KLZH in the late 1990s.

In the 1980s, our group (H. P. Neukom, B. Schilling, T. Läubli) devoted much time to GC technology, first coping with the numerous mechanisms causing quantitative deviations in classical split/splitless injection, such as holding the sample vapors in the injector chamber before they enter the column or achieving a given split ratio during an explosion-like sample evaporation. The real insights into the vaporization process only came in the 1990s, as we learnt to use the fluorescence of perylene for the observation of solvent evaporation ${ }^{[3]}$ and an apprentice brought a video camera from his father to record the process. M. Biedermann, first apprentice, but soon a key member of our small group, prepared a $\mathrm{CD}$ with disturbing films in slow motion. We settled on two options: hot needle injection with nebulization of the sample in an empty injector liner and fast autosampler injection forming a band of liquid to 
be stopped by a low thermal mass packing, the first involving a long, the second a short syringe needle. ${ }^{[4]}$ These techniques were described in detail in a book, the third edition of which was published in 2001. [5]

On-column injection, introduced by my father and me around 1977, ${ }^{[6]}$ avoided these critical steps, ${ }^{[7]}$ but there were also new phenomena, the investigation of which introduced us to large volume sample introduction. Sometimes we observed peak deformation in the later eluted parts of temperature-programmed runs. Using whitish etched glass capillaries and a glass pane for observations in a heated oven, the flow of the sample liquid along the column wall could be observed (turning the column grayish), which explained this band broadening and pointed out the importance of wettability of the column surface. ${ }^{[8]}$ Uncoated precolumns were effective as 'retention gaps', focusing the bands again at the entrance of the coated column. ${ }^{[9]}$

The solvent effects (solvent trapping and phase soaking ${ }^{[10]}$ ) were other important corner stones. They commonly sharpen the peaks eluted after the solvent, but may also distort peaks, particularly when eluted before the solvent or when a component severely overloads the column. Solvent trapping in the flooded column inlet was investigated with whitish glass capillary pre-columns, disconnecting them from the separation column at various moments (heat-shrinkable PTFE sleeves) to vent part of the sample material.[11] Mastering solvent trapping enabled the injection of large volumes (e.g. $100 \mu \mathrm{L})$ of hexane and obtaining sharp peaks for volatiles like octane without loss: ${ }^{[12]}$ solvent evaporation in the GC system is far more selective and easier to handle than other reconcentration techniques. Volatiles are retained in the solvent film up to the end of solvent evaporation.

To investigate phase soaking, B. Schilling broke a column into 13 pieces and reconnected these again to observe passage of a peak at these points. Phase soaking takes place in the coated column in the neighborhood of the solvent band or an overloading peak (swelling the stationary phase). ${ }^{[13]}$ A thorough description of this technical background is given in ref. [14].

In 1984 the solvent effects and the retention gap technique were used to couple HPLC on-line to GC, transferring a 270 $\mu \mathrm{L}$ fraction into an uncoated precolumn of $50 \mathrm{~m}$ in length. ${ }^{[15]}$ This was the start of a technology which was highly successful for the KLZH. First we used two instruments built ourselves, then five fully automated instruments incorporating our technology ${ }^{[16]}$ which became available around 1990. Methods were developed for which the high separation efficiency of HPLC, the precision of locating the relevant frac- tion by on-line HPLC detection and automation of such sample preparation were great steps forward.

Nonetheless, on-line HPLC-GC was a flop: only 200 instruments were sold in the 1990s. It was considered too complicated. Only in the years after 2010 was the technique revived, since there was no reasonable alternative for mineral oil analysis in food.

Technology was not our main occupation, but it was a substantial investment of tax money. Being a leading contributor to a technology today running on probably more than 200,000 instruments is, of course, a great satisfaction, but the investment was well amortized by reliable results (our results were hardly ever questioned), better methods and more efficient trouble shooting - it was the foundation of our later work. Even today, analytical technology is not trivial, and if a laboratory should work efficiently, some investment into the technology, such as thorough trouble shooting and testing of alternatives is a prerequisite.

Around 1990 capillary GC hit its peak - the competence of the analysts started to decline. The pioneers either retired or moved up in the hierarchy. Instruments were sold with the argument that pushing the start button is all it takes; education would no longer be necessary. Universities stopped research in chromatography and with that also education declined. For instance, for standardized methods, anything beyond 1-2 $\mu \mathrm{L}$ split or splitless injection became unacceptable, as it would ask too much from the analysts.

As for many other techniques, the loss of competence is an economic disaster: a large investment is lost due to poor passing on of the know-how - no newcomer will read the thousands of papers (more than 100 from the KLZH alone). In the 1980s and 1990s I taught more than 200 courses on GC technology worldwide, but this could not provide the required education. I advocated an internationally organized education with diploma, based on a compilation of the minimum knowledge to be expected (taking into account the vanishing competent teachers). A pilot course $(4 \times 3$ days $)$ started in Torino in 2001, but it would have required a full-time commitment to carry it further on. It hurt to see that readily available, better techniques were left idle. Also instrument development into improved technology was stopped as it found little demand.

\section{Well-elaborated Methods}

I was, of course, neither the first nor the only person to notice that the technology applied often lagged far behind that available. The public reputation of analytical chemistry declined because of too many poor results. As a reaction, 'quality management systems' were created, methods 'standardized' or at least 'validated' and laboratories 'accredited'. Audits came up to check, e.g. whether the refrigerator was really at the correct temperature. It seemed a desperate move, as it failed to catch the problem at its root. As it was little convincing, such 'quality management' had to be implemented with force, which neither promoted personal commitment nor attracted creative people to analytical chemistry.

Most analytical methods are poorly elaborated and far from the achievable. Rather than investing into time-consuming validation of poor methods, often with sophisticated statistics, methods should have been improved. However, this failed for a simple reason: analysts work on a method just up to the point that it works in their hands, on their instruments and for their purpose. The column already hanging in the GC oven is used and the techniques they happen to know. No alternatives are investigated. Nothing else can be expected from efficiently working laboratories: why should a method be further elaborated to give it away to others for free?

The development of well optimized methods easily costs $€ 500,000$ and is, therefore, a major investment. It hardly ever happens, as nobody is motivated to finance it. The problem is not new: in the early times, each expert developed his own computer software, but this was rapidly replaced by commercial software of superior quality. It followed simple economy: if many users share the costs, it will be cheaper even if the producer puts a good proportion in his own pocket. The situation of analytical methods is similar, but the problem did not get solved: many analytes are measured by many laboratories. Each one invests considerably into the method and all are likely to go through the similar problems and pitfalls. The total costs probably far exceed those of a single well elaborated method all could use more or less right away.

In analogy to computer software I suggested sharing costs of method development through sale or licenses: companies buy promising approaches, finance further elaboration, perhaps at universities, and sell the method together with all materials that render its application easy and safe, including standard solutions, test samples as well as software for data handling and reporting. These methods still need validation and if all steps are well under control, such validation should provide reliable data. However, verification is more important, as the performance of chromatography and mass spectrometry tends to drift. By adding standards at various points of a 
procedure, the performance at critical steps can be checked in the chromatograms of each analysis. ${ }^{[17]}$ Several companies studied the concept, but saw too much risk in pirate copies.

In the end, the three principal problems of chemical analysis were not solved: adequate education of the analysts, use of analytical technology at its best and the development of methods exploiting the full potential. Analysts lack a professional organization that cares about the common superordinate interests.

\section{Adulteration of Edible Oils}

Our first major application concerned the detection of adulterated edible oils, such as olive oil. Initially control had primarily been performed through the composition of the fatty acids. In the 1980s the analysis of the sterols was successful as it enabled unambiguous detection of rapeseed oil through brassica- and campesterol. We analyzed a substantial number of olive oils, but only detected a single, clumsy fraud, leaving us with the question whether frauds were no real problem or we were just unable to detect them.

We decided to go for the second: through contacts in Italy I knew about a substantial market for 'invisible' admixtures. The control methods had been standardized, with numerous values 'defining' olive oil, which invited frauds to adjust their admixtures to these values. As profits were huge, the costs for checking conformity with the limits were negligible. Standardizing the methods to detect frauds was, in fact, as inadequate as chasing doped cyclists by a fixed set of well-known methods.

It cost 2 years of developing new methods to surprise frauds by looking at parameters they were not prepared for. The first assessed the complex mixture of minor components - a rich source of components which could serve as markers for low-price oils. ${ }^{[18]}$ The second analyzed the sterenes, the dehydration products of sterols formed during bleaching and deodoration, i.e. indicators of raffination (admixed oils must be refined to avoid organoleptic detection). Their pattern also gave information about the sterol composition of the added oil.[19] A third method on an isomerized $\Delta 7$-sterol was devised for added high oleic acid sunflower oil.[20] Using these new tools, admixtures were revealed for almost half of all olive oils, particularly those in cans or glass jars containing vegetables or fish.[21]

Since we were making the accusation of adulteration, we had to disclose the analytical methods and results, but now it was of advantage that all three methods involved on-line coupled HPLC-GC which could not be implemented so easily and rapidly by the fraudulent producers. It must have been such a shock that even 10 years later many thought that the KLZH would detect 'everything'.

In this period (1989 to 1995) there were two highlights. In 1993 I taught a seminar on HPLC-GC for edible oil analysis in Milan: the seminar had to be repeated and filled the room twice with 60 persons even though it was held in Italian. It would have been interesting to know more about these participants and their motivation. During a similar event the demonstration of the analysis revealed a well-known brand of olive oil as a fraud. The same oil on the market in Zurich, however, was not adulterated, which was the great reward for our work.

Also many other edible oils had been adulterated, such as sesame, safflower or walnut oil, but the producers obviously did not expect smart control and frauds were not as 'professional' as for the olive oils.

\section{The Lesson from BSE}

In the 1970s we detected tetrachloroethylene at unacceptably high concentrations in the tap water of Zürich (100-150 $\mu \mathrm{g} / \mathrm{l})$, shortly later also in feeds containing slaughterhouse wastes and, as a result, in eggs, chicken and pork. The source was a plant extracting the fat from slaughterhouse wastes and dead animals. It was great news that the process was to be changed, water vapor replacing the solvent.

A few years later, news about cows which slowly died from brain degeneration (bovine spongiform encephalopathy, BSE) came from the United Kingdom. It was caused by a then unknown infection via slaughterhouse wastes and could take many years to break out. It would take years to know whether humans were also infected. This escalated to a British minister eating beef at the TV to appease the population - perhaps with the hidden thought that an additional steak would not change anything for his own health. The possibility that most of the European population could die by a variant of the CreutzfeldtJakob disease could not be ignored - also Switzerland was hit by a large number of BSE animals. Only years later it turned out that humans happened to be resistant: the death toll was 'only' around 200.

The general population rapidly forgot (or never even noticed) that it scraped past a disaster worse than anything experienced before - because of the change in processing waste. It reminded us of our ultimate task: avoiding a disaster of this type - though BSE was not the fault of a neglectful authority: prions were unknown at the time.

Chronic intoxication by chemicals has a similar risk profile: effects evolve slowly, perhaps over decades, and when it is detected, several 100 Mio individuals may be affected. Most likely it will take many more years to identify the cause, e.g. a component in a printing ink or a defoamer used for processing potatoes. Remedies may be impossible. Rather than a rapid dramatic effect, chronic intoxication is likely to make us feel bad, weakening organs, rendering us more susceptible to disease, affect fertility or cause tumors. No one is prepared to waste his life because of a substance that had carelessly been used to save a bit of money or promote sales by a more spectacular packing. Such a disaster may be due to an undetected toxicity of a regulated substance, but is more likely to be caused by one of the many substances so far outside the radar screen.

Most chemicals entering our foods are harmless, but by sheer probability some of the probably more than 100,000 we are continuously exposed to will affect our health - if it were 1 out of 100, it would be 1000 substances. ${ }^{[22]}$ There is no easy way to find them, but the dramatic effect they might have should motivate industry and authorities to do their best to detect them. All this seems obvious, but is probably not communicated well enough.

\section{BADGE from Can Coatings}

Sometimes an unknown peak disturbed the HPLC-GC analysis for the detection of adulterated oils. In December 1995, M. Biedermann identified it as bisphenol A diglycidyl ether (BADGE). In fact, the oil was from canned sardines and BADGE had migrated from the internal coating of the can. This was a milestone with a profound effect on the perception of migrates from food contact materials (FCM).

Based on in vitro tests, BADGE was classified as a genotoxic carcinogen and the Council of Europe as well as the Swiss legislation required that it was undetectable in food at a detection limit of $20 \mu \mathrm{g} / \mathrm{kg}$. Numerous oily products in cans exceeded this value 1000 times, which prompted the largest scale confiscation in Switzerland that ever happened - and a shock throughout Europe. Lawyers came from all over, with arguments like that our method was not internationally recognized - of course not, if nobody had performed controls before. Luckily, years later it was established that BADGE was not carcinogenic in vivo.

BADGE opened eyes. So far FCM seemed nice and clean and even the smell (including that of PVC plasticized with phthalates) was perceived as positive (technical progress). Chromatograms produced a different picture: in extracts from epoxy coatings, BADGE was a minor peak 
in a 'forest' of others. Apparently nobody knew their identity, nor had somebody cared about safety. We identified more than a hundred, but failed for more than half of the material, as the components must have undergone more complex chemistry (curing of the coating occurs at $200-220{ }^{\circ} \mathrm{C}$ ). I was even more shocked about industry arguing that there was no need to identify reaction products as they are formed from evaluated starting substances (BADGE and bisphenol A!). It seemed far removed from science and characterized the level of discussions, perhaps also how industry thought it could deal with authorities.

On an evening in 1998, the EU legislator for FCM phoned and wanted to talk to the 'mad man' in Switzerland. After 2 hours of discussion - he engaged me as opponent to industry - which he meant literally: the first broad discussion was initiated by a disputation between a leading industry man and me placed in the center of an audience of probably around 40 persons placed as a ring around us, perhaps inspired by the fights in the Coliseum (he was from Rome). I became his consultant and intense collaboration started, particularly over weekends, public holidays and Christmas/New Year. First it was on legislation on BADGE and an even less evaluated material industry had switched to (novolac glycidyl ether, NOGE), then on all sort of subjects around plastic materials, testing procedures, correction for exposure (fat reduction factor) and the 'Superregulation' (which was turned down by industry in late 2004).

Work for the DG-SANCO of the European Commission catapulted me into a new sphere. I participated at the many newly initiated 'Task Force' meetings with industry which lasted 2 or 3 days. Subjects around FCM were debated to exhaustion. It opened the eyes to the way decisions were taken and who was the real authority: it was the person bringing up the convincing argument at the right moment; 'Switzerland' had probably more influence on the EU regulation on FCM than any member state. During the meetings with the member states I was sitting next to him to support and correct him when necessary.

'Switzerland' was warmly welcomed, but in reality it consisted of a single person expressing his personal view and doing this as a hobby (official Switzerland is not an EU member and had hardly any relationship to the Commission).

The evenings during the Task Force meetings were allegorical: we separated, industry people eating and sleeping in another class of restaurants and hotels than we 2-3 persons paid by public money (payment meaning expenses - we worked in our spare time). This taught me the im- portance the public attaches to our work. The situation was also palpable in terms of location: the legislator sitting in a small, cheaply furnished office (building rented by the Commission) versus the many industry associations residing in representative buildings in the richer quarters like strangulating the Commission. The public might not be aware of this imbalance between 'its' authority and industry.

I also learned about the weakness of a national authority, particularly one outside the EU, opposed to an international industry that intervenes high up in the hierarchy of the Commission when it risks losing. It takes years and endless discussions to implement most obvious requirements and I now understand why persons starting work for authorities lose their motivation.

In 1998 the Council of Europe formed a group working on coatings (the Commission had no intention or capacity to regulate coatings). After 5 years and many meetings in Strasbourg, industry only accepted that migrates from coatings have to respect Article 3 of the EU Framework regulation (which was anyway valid since 1976). Dietary exposure could now be taken into account (to get the tolerable migration sharper to the limits of toxicology) and 'read across' or 'in silico' toxicology (tentative evaluation by comparison with other substances) would be sufficient (Framework Resolution AP(2004)1). It was interesting how this decision came about. It followed a period without meetings because of health problems of the responsible person at the Council of Europe (Peter Baum; he had no substitute or assistant) and the work had then to be concluded in a hurry as Baum retired without replacement. Industry proposed a text, and since the few delegates from authorities did not insist on a more substantial one, it passed. Not even this was implemented, however, as became apparent when we required the safety evaluation for the dominating migrant from epoxy coating, cyclo-diBA, in 2011. ${ }^{[23]}$ Thus the overall achievement was limited to having pointed out the problem.

\section{Acrylamide}

In April 2002 I heard from a Dutch colleague about the formation of acrylamide at levels up to $\mathrm{mg} / \mathrm{kg}$ by baking and frying certain foods. Being an industrial chemical, acrylamide was well evaluated and classified as a probable carcinogen for humans. A well resorbed carcinogen at such concentrations was a shock, as others formed during heating, such as benzopyrene, were strictly limited to 100-1000 times lower levels; extrapolated from animal experiments, slightly brown French fries have a far higher potential of carcinogenicity than a black sausage grilled over a barbecue that every child knows to avoid.

On the next day we started developing an analytical method (GC-MS). As GC does not really tolerate injection of water, we first tried extracting potato chips with organic solvents, such as acetone. In the first sample analyzed we found $15 \mu \mathrm{g} /$ $\mathrm{kg}$ acrylamide. Repeating this extraction overnight, we found another $45 \mu \mathrm{g} / \mathrm{kg}$, which made us suspicious. Then we nonetheless extracted with some water - and found roughly $500 \mu \mathrm{g} / \mathrm{kg}$. It was not the first time to note that extraction of solids, even when finely ground, may be difficult. Water was removed azeotropically with propanol. The other problem was linked to the small and unselective molecular mass $(71 \mathrm{Da})$. As adsorptivity required a Carbowax stationary phase, acrylamide was eluted with less polar substances of higher molecular mass, which resulted in interference of fragments from these. This was overcome by chemical ionization. ${ }^{24]}$

In early summer 2002 we knew that roasted, baked or fried potatoes were the main sources of exposure and that the reducing sugars, mainly formed during storage of fresh potatoes at low temperature (4 $\left.{ }^{\circ} \mathrm{C}\right)$, were the key parameter to control. ${ }^{[25,26]}$ A portion of brown roasted potatoes (roesti, hash browns) easily contains more acrylamide than all other foods consumed during several weeks. A. Pfefferle and D. Bazzocco, professional cooks teaching at the School of Hotel Management Belvoirpark, Zürich, spent days in our laboratory kitchen preparing roesti, combining high culinary quality with low acrylamide contents. Using potatoes low in reducing sugars and avoiding high temperatures, acrylamide could be reduced from 5000 to $150 \mu \mathrm{g} / \mathrm{kg}$. This roesti was crispy, slightly brownish, but no longer dark. ${ }^{[27]}$ Such exercises were later repeated for French fries.

Still in 2002, M. Biedermann tested many ingredients with regard to accelerating or slowing acrylamide formation in baked goods, which revealed ammonium carbonate as potent catalyst.[28] In fact, products prepared with this salt, such as gingerbread, contained far more acrylamide than those with sodium carbonate, for example.

In Switzerland the relevant stakeholders took the message. Producers of prefabricated French fries and roesti strictly bought in potatoes low in reducing sugars and stored them at temperatures high enough to prevent liberation of sugars. In fact, French fries served in Switzerland contain several times less acrylamide than most offered abroad (in a campaign in 2003, the median of 157 samples was 76 $\mu \mathrm{g} / \mathrm{kg}^{[29]}$. Exceptions were the fast food chains with more than four times higher values for sugars and acrylamide. ${ }^{[30]}$ 
Retailers agreed to offer a special line of raw potatoes low in sugars for domestic preparation of roesti and other baked or fried products (red bags). A producer of fryers well understood that the oil temperature should fall towards the end of the frying process (most of the acrylamide is generated in the crust formed in the last moment), but he would only develop such a fryer if a legal requirement ensured that it could be sold - and this was never implemented.

Acrylamide evoked divergent reactions. On the one hand it was widely agreed that the toxicity of acrylamide clearly exceeded that of all other known food contaminants, possibly being responsible for more than $1 \%$ of all cancer cases, i.e. comparable in number to victims of road accidents. On the other hand, there were renowned scientists unable to accept that roasting potatoes may result in a potent carcinogen, using arguments such as that humans have been exposed to such products for thousands of years - which is obviously inappropriate, firstly because potatoes were introduced rather recently and, secondly, humans do not become immune to carcinogens, as shown by the aflatoxins. This emotional interference with science was subject of a remarkable paper by Ruden. ${ }^{[31]}$

Progress made in Switzerland was soon slowed by a lack of activity in other countries. Enormous amounts of money (probably more than a billion Euros) were spent for further research, even though the results were always essentially the same. Some suspected that this just served to gain time. To prevent legal regulation, industry reacted proactively by a 'tool box' to reduce acrylamide formation, ${ }^{[32]}$ and when EFSA concluded from a costly monitoring campaign that "the trend analysis did not show any major changes in acrylamide levels during the 2007 to 2010 monitoring period", ${ }^{[33]}$ i.e. that these tools were not broadly implemented, the wave of concern had ebbed away. Even in Germany, where the problem was taken seriously, it was considered too complicated to more carefully select and store potatoes to keep reducing sugars low (as successfully done in Switzerland). The KLZH was the only authority worldwide to confiscate products because of extremely high acrylamide content: a baby biscuit and chips.

In 2005, after having published 22 scientific papers, we largely stopped our work, as further investment of public money seemed no longer justifiable. No legal limit or other rule was imposed anywhere in the world and it was disturbing to see how authorities returned to the routine of controlling substances of far lower concern. In all: a huge investment, but the consumers profited little. In my eyes it damaged credibility of authorities and co- herence of risk management: if acrylamide is not taken seriously, what is the risk considered relevant to take measures?

Acrylamide also reminded us that we have no overview of the toxic substances in food. All of a sudden a 100-1000 times greater health risk emerged - but still only accounted for a small proportion of all cancer cases. It supports the suspicion that we still miss out many or even most substances potentially affecting human health.

\section{Plasticizers Migrating from the Gasket of Lids}

The next major project followed straight away - and was different, though again a mixture of analytical challenge, tilting at windmills and requiring a large investment over some 10 years.

In 1998, a Swedish paper showed that epoxidized soy bean oil (ESBO), a plasticizer, migrated from the (PVC) gaskets of lids into infant foods in glass jars sometimes beyond the tolerable daily intake (TDI). I put this aside, assuming that the public is so sensitive to infant products that the problem would rapidly be solved. This was wrong: surveys performed in 1999 and 2001 by the British and the EU authorities revealed no improvement. Nonetheless nobody took measures. The British authorities merely commented by a beautifully worded "it would be prudent that action should be taken to reduce the levels of ESBO in these products in order to restore the safety margin incorporated into the TDI".

In 2004 we became concerned that we would be accused of not having taken measures to protect babies. We developed a method to measure ESBO, screened the Swiss market and were the first to stop the sale of some products. ${ }^{[34]}$ Considering the low fat content of infant products (1-4\%), the interest turned to oily sauces (e.g. pesto) or vegetables and fish in oil. Indeed, most of the 86 products analyzed contained ESBO clearly above the limit $(60 \mathrm{mg} / \mathrm{kg})$, with a maximum at $560 \mathrm{mg} / \mathrm{kg}$. Panic arose among industry producers, reminiscent of the BADGE crisis, and the same people came to visit us again (the same manufacturers produce cans and lids) to plea for a mild solution. The Swiss authorities decided to temporarily lift the limit for ESBO in order to prevent ESBO being replaced by plasticizers of more concern. This was well justified: we had a guest from the official food control of Tokyo and in one of the samples she had brought we found no ESBO, but di(2-ethylhexyl) phthalate (DEHP) - even further above the (lower) limit.

Alarmed retailers wanted lid producers to declare the plasticizers used, but only received answers like 'contains no ESBO' when it contained phthalates, for example. The lid producers refused, but obviously underestimated the potential of analytical chemistry: in short we had a method that provided detailed quantitative data.

We developed three methods for measuring the various plasticizers in foods: online HPLC-GC after a 1 min transesterification for ESBO, direct injection of the oily extract with selective thermal desorption for the more volatile plasticizers (totally about a dozen, including phthalates) and GC-MS after transesterification for the polyadipates. The polyadipates were most demanding, since the measured (transbutylated) adipate had to be corrected for the alcohol moiety and the end capping by a conversion factor (determined from the low molecular mass oligomers of the polyadipate used) and for the part of a mass below 1000 Da. Many polyadipates are used and we remained the only laboratory to perform the analysis, who were independent of obtaining that used for calibration.

In 2005,147 out of 158 products from the Swiss market were non-compliant, even though nearly all were far from the expiry data (up to which migration progresses). [35] In the 91 products with ESBO in the gasket, the average ESBO concentration in the food was $216 \mathrm{mg} / \mathrm{kg}$. The gaskets of 38 products were plasticized with phthalates, the migration of which reached $825 \mathrm{mg} /$ $\mathrm{kg}$ DEHP (illegal use, limit for legal use, $1.5 \mathrm{mg} / \mathrm{kg}$ ). Later, products from outside Europe with 1000-2000 mg/kg phthalates were detected, among which one with diisononyl phthalate (DINP) in an absolute amount as high as $0.5 \mathrm{~g}$ in the $300 \mathrm{~g}$ jar content. This might have been the worst failure rate ever of an enforcement campaign.

We had learnt to care about support from other countries and invited colleagues from eight European authorities to bring samples and analyze these in our laboratory. As no other laboratory had the methods running, this was the way to bring the problem to their attention. It did not take long until the Danish authority concluded that only their king could free them from a massive confiscation - or the European Commission. Indeed, EU legislation was enacted exempting the non-compliant lid industry from enforcement by a strong increase of several legal limits for 4 years (Regulation 372/2007; it needed prolongation for another year up to April 2009).

Industry experts admitted that they knew about the problem, but "nobody said anything". They even claimed that it is not possible to produce compliant lids for oily foods and that legislation needed to be adjusted. To check this we collaborated with a small lid manufacturer. Indeed, he 
identified a promising polyadipate plasticizer with a low proportion of constituents of a molecular mass below $1000 \mathrm{Da}$. The obstacle was the high viscosity of the resulting plastisol (PVC/plasticizer mixture, deposited into the lid through a nozzle). He modified his machinery and started selling compliant lids in summer 2005. Hence it was possible, but the other producers insisted in using their standard machines - and the derogation of the Commission permitted it. The small company ended up being ostracized by the others. Protection of industry seemed more important than protection of consumers.

The development of new gaskets presupposes testing, i.e. determining the migration over several years (the usual shelf life of such products). Conventional simulation during $10 \mathrm{~d}$ at $40^{\circ} \mathrm{C}$ seriously underestimated long-term migration. Together with an Italian laboratory (SSICA in Parma) we mounted a project, largely financed by the lid industry, to find a method for accelerated testing, but with the small margin between the migration and the legal limits it failed: ${ }^{[36]}$ testing had to be performed under real conditions and over real durations.

In 2006 we invited to a 2-day workshop on the analysis of plasticizer migration, limited to 20 delegates from authorities and 25 (paying) persons from industry, with many lectures and practical demonstrations. Also the European Reference Laboratory (EURL) for FCM in Ispra, supporting the national control laboratories, put the methods for analyzing the plasticizers on the agenda. Many national laboratories invested most of their resources into establishing these, but none succeeded for all of them and, hence, were unable to start control. This was a huge waste of resources and demonstrated the need for better collaboration: as the lids are not the only FCM to be checked, the work must be shared; a few laboratories should analyze for all.

In 2011 we tried a great leap forward: together with the control laboratory of Stuttgart we offered each European country the analysis of 20 oily products in jars. Totally 411 samples were analyzed within about two months - less time than needed for a single laboratory to establish the methods, which demonstrated the drastic saving achievable by collaboration. The extra costs for the two analyzing laboratories were modest, as they would have analyzed more samples from their home market otherwise. The results were miserable: even though most samples were far from the expiration date, $24 \%$ exceeded the legal limits, often by far, or non-authorized plasticizers had been used.[37]

In 2013, 4 years after the exemption ended, another European campaign was initiated, this time focusing on the compliance work performed by the supply chain. As nothing like this had been done before, we proposed a procedure and provided explanatory texts as well as letters to request documents. Now 12 countries participated with 48 samples carrying lids from all major manufacturers. Not a single product came with satisfactory compliance work. ${ }^{[38]}$ Mostly conventional simulation was applied of which the lid manufacturers knew that it underestimated real migration. Two producers had performed long term tests, but using conditions resulting in unrealistically low migration. Some others provided no data at all. Being aware of their inadequate testing, most manufacturers delegated the responsibility for compliance to the packers, which would have meant that the packers ran tests for several years before using the lids (provided the results had turned out positive, which would have not in many cases) - quite an absurd conception and, in fact, no packer performed it. This time $29 \%$ samples exceeded the migration limits, all of which had test data showing compliance (the other samples were not even analyzed).

The most disturbing result of this campaign: no participating authority had measures available to react against business operators having performed poor compliance work or none at all. The concept of systematic compliance work was not enforceable. Also in this point our achievement is limited to having pointed out the problem.

\section{Mineral Oil}

Mineral oil kept us busy through most of my career. Back in the 1980s a biscuit was found to contain $1.5 \%$ of a mineral oil product used as release agent (to avoid sticking to the mold). Shortly later, on developing a method for uncovering irradiation for food conservation (by on-line HPLC-GC), we detected that commercial hazelnuts were contaminated by mineral oil - those from my garden were not. It took a while to find out that these hydrocarbons were from jute or sisal bags, the fibers of which had been treated with 'batching oil' (a brownish, rather crude mineral oil fraction) to improve spinning properties.

The problem of contaminated hazelnuts was rapidly solved: the suppliers, mostly in Turkey, switched to bags made with plant oils for batching the fibers. It was more difficult for other foods. Swiss chocolate was contaminated by batching oil at up to $700 \mathrm{mg} / \mathrm{kg}$. Since the bags with the cocoa beans were bought from the spot market at European ports, there was no direct access to the producers. We invited the main jute bag producers (Bangladesh) and offered them chocolate to which we added about the amount of batching oil they already contained in front of their eyes. They refused to eat it, but also "to produce special bags just for Switzerland".

We were the only laboratory to analyze mineral oil in foods (on-line HPLC-GC). On the one hand this was a drawback, as no other control authority was able to produce data and support us. On the other hand, it prevented a scandal that could have ruined the reputation of Swiss chocolate.

Not that the evaluation of mineral oil had been unclear: in 1989, the Scientific Committee on Foods (SCF, predecessor of the EFSA) published an opinion from which legal limits of 0.3 or $3 \mathrm{mg} / \mathrm{kg}$ food could be derived, depending on oil quality (the quality of batching oil not even being considered).

After several years without progress, we tried to increase our efforts. In 1996 a doctoral student ( $\mathrm{S}$. Moret) constructed the most complex automated HPLC-GC system ever built to determine mineral oil aromatic hydrocarbons (MOAH) in foods. The mineral oil was isolated from the food, particularly from the fat, on a large HPLC column. The eluent $(6 \mathrm{~mL}$, including dichloromethane) was evaporated on-line in a warmed $5 \mathrm{~cm} \times 1 \mathrm{~mm}$ i.d. glass tube containing coarse, partially silylated silica gel. The reconcentrated hydrocarbons were transferred to a smaller amino HPLC column for preseparation of the MOAH by ring number, then analyzed by GC. Largely alkylated polyaromatic hydrocarbons, including thiophenes, were detected. [39] Indeed, in 1999 the association of the chocolate, biscuits and confectionary industry (Caobisco) established that the jute and sisal bags sent to Europe should be virtually free of mineral oil.

Many other foods were also contaminated by mineral oil. For instance, in Switzerland rice was stored for several years to ensure supply in case of war, but then needed to be refined again. To give it back some gloss, this rice was sprayed with 'food grade' (white, i.e. MOAH-free) mineral oil at $1000-3000 \mathrm{mg} / \mathrm{kg}$. Industrial bakeries used mineral oil as release agents. Every week a truck-load of oil was brought to a plant near Zurich and left it again in the bread and other bakery products. Concentrations again reached 1000-2000 $\mathrm{mg} / \mathrm{kg}$. These and some other practices were stopped. The environmental contribution was also revealed to be substantial: plants are contaminated with mineral oil, mainly lubricating oil from diesel engines. These oils are hardly degradable and accumulate in the soil, with particularly high concentrations in compost and humus formed by decomposed leaves and needles below trees. ${ }^{[40]}$ No surprise, nobody wanted to hear this. 
In 2008 there was broad demand for our mineral oil analysis in the case of the contaminated Ukrainian sunflower oil. It motivated us to further invest into the methods, such as for routine measurement of MOAH and characterizing these by comprehensive two-dimensional GC (GCXGC). It culminated in a 2-day workshop at the KLZH organized jointly with the European Commission on methodology and background information about mineral oil contamination of foods.

In $1995,50-150 \mathrm{mg} / \mathrm{kg}$ mineral oil was detected in powders for infant formula. It had migrated from boxes of recycled board printed with mineral-oil-based inks through the internal paper bags. The producers reacted by introducing an aluminum foil into the internal bag. At this time the Kantonales Labor St. Gallen joined us and we found many other products contaminated by paperboard boxes. However, we were ineffective in implementing improvements: ${ }^{[1]}$ the producers of recycled paperboard saw the main problem in the printing inks and the ink producers in the recycled board. It took until 2009 and that I worked as expert in the Bedarfsgegenständekommission of the German Federal Institute for Risk Assessment (BfR): The German legislator (BMELV) immediately launched a project for regulation. It already had sponsored a project on an overview on potential migrants from recycled paperboard, ${ }^{[42]}$ including a market survey on mineral oil contents of products from the German market. ${ }^{[43]}$ Now many laboratories started analyzing mineral oil, mostly by on-line HPLC-GC. [44]

The mineral oil from paperboard boxes found an overwhelming echo in the media, first in Switzerland, then in Germany and finally worldwide by the $\mathrm{BBC}$ and the media linked to it. The world may be unfair: soon the German legislator found itself accused of insufficiently protecting the consumers - it became victim of its own initiative.

Recycled paperboard for food packaging is problematic not only because of the mineral oil. Using comprehensive HPLC $\times$ GC and GC $\times$ GC, we detected at least 250 substances potentially migrating into dry food at concentrations above the threshold of toxicological concern specified by the German government. ${ }^{[45]}$ As the use of recycled paperboard is desirable for sustainable use of material, functional barriers became the favored solution, either built into the internal bag or as a layer on the paperboard (if no internal bag is used). We assumed an active role in developing a method for measuring barrier efficiency ${ }^{[46]}$ and initiated a working group at the Joint Industry Group (JIG) of the Schweizerisches Verpackungsinstitut (SVI) to establish a standard specifying the minimum required barrier efficiency and give the packers confidence in adequate materials - according to the motto better to support a positive development than to criticize a poor one afterwards.

Mineral oil is probably the largest food contaminant, widely used in cosmetics and medicine, recommended by some medical doctors to substitute edible oil in salad dressings to fight obesity, but when looking for a safety assessment, the data are meager (EFSA opinion 2012[47]). Evaluation by gut feeling must have suggested low toxicity, but among the aromatic hydrocarbons (MOAH) are genotoxic carcinogens, among the saturated ones (MOSH) persistent, strongly accumulated constituents (as noted by the evaluation in 1989).

In 2002, to attract more attention to the subject, we determined mineral oil hydrocarbons in human milk - and found up to $1500 \mathrm{mg} / \mathrm{kg}$ related to fat after application of breast salves. ${ }^{[48]}$ Later, a collaboration with the university hospital of Innsbruck gave us the opportunity to analyze subcutaneous abdominal fat tissue from Caesarean sections ${ }^{[49]}$ and recently a similar collaboration with the Medical University of Vienna to determine the MOSH in various human tissues. Concentrations reached $1400 \mathrm{mg}$ / $\mathrm{kg}$ in mesenteric lymph nodes and spleen, and for a quarter of the subjects (average age, $67 \mathrm{y}$ ) a body burden exceeding $5 \mathrm{~g}$ mineral oil hydrocarbons was calculated. This is not necessarily an indication of a health issue, but deserving of a particularly careful safety assessment - by more than gut feeling. Accumulation in human tissue was probably underestimated by previous evaluations: concentrations reached those found for the highest dose in animal studies. I am confident that these data will effect a more careful consideration of mineral oil.

\section{Compliance Work by Producers}

According to the concept of self-control, legally laid down, e.g. in Switzerland, producers have to ensure compliance with legal requirements (based on specific legislation if available and otherwise own evaluation); authorities perform spot checks. In the field of FCM, however, it largely worked the other way: industry waited until one of the few active European enforcement authorities demonstrated non-compliance and then asked for several years of time to get the problem solved.

This 'wait and see' approach was convenient for industry, as just a small minority of the problems was brought up and a substantial part of the work, such as the development of the analytical methods and much data on the background was financed by these authorities. For consumer safety this leads nowhere. A new approach was needed.

Industry lamented that it was unable to do the compliance work since it would not know the composition of the material bought in. The whole responsibility was usually shifted to the final producer, often rather small companies completely overtaxed with this task. In fact, it seemed obvious that this would never work, as FCM usually release dozens if not hundreds of substances into food at potentially relevant concentrations, but industry did not search for solutions. The solution is in sharing the work.

In 2006, the European Commission enacted the so-called GMP Regulation (2023/2006). It provided little specific and enforceable requirements, but was the basis to build up a stringent system for the supply chain to share the compliance work. Together with J. Stocker and R. Colwell (British branch of Heinz) and G. Marmiroli (INCAM, today Ardagh, can producer) I elaborated three key papers interpreting existing legislation, proposing a system clarifying accomplished and outstanding compliance work at each stage of production and illustrating the functioning by compliance work for a hypothetical lid. ${ }^{[50,51]}$ In essence, each operator is responsible for the substances he introduces and has the choice of either concluding the related compliance work or to delegating it explicitly to his customers. Each operator in the chain should know the burden of compliance work linked with a material he buys.

Compliance work should be concluded as early in the manufacturing chain as possible to avoid that many customers, e.g. of an ink or adhesive, have to perform virtually the same work. At the stage a substance is introduced there is a maximum of competence and also the possibility to select compounds with easy compliance work (low and well investigated toxicity). The producer of the final material, obliged to conclude all work, should know what is left to be done.

In Germany a working group with representatives from all relevant authorities approved these principals. ${ }^{52]}$ Austria introduced the same text into the 'Codex Alimentarius'. In 2013 the main logic was introduced into the EU guidelines for Regulation 10/2011.

In Switzerland, the JIG of the SVI established a working group that implemented these principals into a position paper, prepared a check list and organized courses for 'reading' compliance documents as well as for 'writing' them. A group of Swiss control authorities elaborated a system for a coordinated control of the compliance work, particularly the supporting documentation in which producers have to record the data and reasoning on the 
basis of which they declared compliance. Reasonable progress was made to implement this system, but it also evidenced a more fundamental problem.

Most compliance declarations (if any are available) end with a disclaimer, sometimes hidden in a wordy text, refusing responsibility and charging the customer to redo all the work - which no one does nor can realistically do. In reaction to this, some food producers and retailers worded the compliance declarations for the suppliers and asked these to sign it. This is dancing on glowing coal, since for almost all FCM compliance work is incomplete: the safety of many starting substances is not assured and usually the major part of the migrating material consists of reaction products and impurities of which often not even the composition is known. It means that hardly any material really fulfills legal requirements.

The situation is in deadlock: producers know that they cannot really declare compliance; customers, such as brand owners and retailers, are aware of this and nonetheless require a compliance declaration, as they are not willing to take over responsibility; also authorities know, but do not know how to react (enforcement cannot take all non-compliant products from the market and legislators cannot rewrite their text in the sense that safety only needs to be assured if easily feasible). Hence it is an 'open secret'; there has been hardly any progress since the task is too large to be tackled and for stakeholders it is better to keep quiet. Some work is not even feasible, as exemplified for a coating applied for restoring domestic water supply. [53]

A more flexible approach is needed to ensure that readily feasible compliance work is done, solutions for the more difficult tasks are sought, but also enables to at least temporarily tolerate that the safety promised to consumers by legislation is only partially ensured. Work plans established in agreement between producers and authorities were proposed:[54] gaps in compliance work should be laid open and a plan established on how and how far it can be closed. At any rate: more needs to be done than some analysis in the laboratory to demonstrate non-compliance.

\section{Risk Assessment}

Much of the work of food control authorities is based on evaluations by risk assessment authorities. I had the chance to complete my career by working for the three main ones in Europe: in 2006 I became expert in the panel on food contact materials (CES MCDA) of the French AFSSA (now ANSES), later in the one on chemical contaminants in general (CES-
ERCA), then also in the German panel on food contact materials at the BfR. From 2004-2012 I was involved in working groups of the European EFSA, the most important of which was on mineral oil, and in $2014 \mathrm{I}$ was appointed to the EFSA-CEF panel.

Setting rules or authorizing the use of a substance means that the responsibility for safety is factually taken over by the public, i.e. by the authorities or, more particularly, by the experts. This is taken respectfully. Experts are carefully selected from usually long lists of applicants. The meetings breathe the spirit of strict science and high ethics - far removed from the disputes of enforcement with their sinners. Great pains are taken to ensure the independence of the experts. This is underlined by the work being virtually unpaid - for honor (or the reputation of the institute experts are delegated from).

This work opened my eyes to the uncertainties. At first glance the safety margins in what may be called regulatory toxicology seem substantial, but they are less so when considering the many crude assumptions. Consumer confidence is of highest priority, but is it justified? It seems so during the meetings, but ever new toxic effects are detected and as evaluations from the 1980s are often considered inconclusive today, this may also happen to our present decisions. As thousands of substances are authorized through this process, a small risk of error becomes substantial and I would not be surprised when one day it would turn out that millions suffer from a chemical the toxicity of which had escaped our examination.

Bisphenol A, a substance used to make polycarbonate (baby bottles) and can coatings, shook the confidence in scientific opinions of authorities to the foundations. In 2010 I participated in the preparation of the first French opinion. The previous evaluations by EFSA had been careful and thorough, according to the current science, but some researchers claimed that far more sensitive effects had been overlooked. Journalists accused EFSA of being biased by industry interests and neglecting work that shows a far higher toxicity. The French parliament wanted to ban baby bottles made of bisphenol A, which prompted the ministry of health to ask for the opinion of the AFSSA.

The panel studied more than 130 recent scientific publications. It was embarrassing to see the many poor papers and the question came down to whether one of them was sufficiently solid to support the emotionalized debate against this substance. In the end the group was less firmly behind the previous EFSA evaluation, but could not really identify substantiated risks. ${ }^{[55]}$ Of course, if there had been just a small risk of $e . g$. obesity being linked to misguided regulation of satiation or metabolism (one of numerous suspicions), the substance would have had to be banned urgently. In this situation the easiest way out is being strict and refusing any suspected risk, but done coherently this would probably block the use of a large part of the currently used chemicals. Hence some risk must be accepted - even though not publicly admitted. In fact, only very few substances have been investigated for endocrine disruption as deeply as bisphenol A. Should they all be re-evaluated - and who would pay for this?

\section{Conclusions on Official Food Control}

Working in consumer protection motivated me to a commitment far beyond the paid working hours, but I cannot deny moments of doubts and frustration. The dominating game of marketing and 'making money' would need a more strict control and authorities defending the public interests as fiercely and cunningly as industry strives for theirs. However, this is hampered by scarce (and further decreasing) resources, structures of the control obstructing their own efficiency, being inadequate for internationally marketed products, insufficient courage to stand for the mission and broad demotivation to engage against industry.

As shown above, most of our activities were not successful in reaching the envisioned goals (which were mostly quite challenging). The main achievements were probably demonstrating gaps and problems, widening the view on food safety and providing related analytical technology, such as comprehensive analysis aiming at producing a picture as complete as possible of the substances migrating into food. Consumer protection is more challenging than I perceived it earlier on and great efforts will be needed to narrow the worrying gap between consumer expectation (legislation) and reality.

Perhaps some more general conclusions referring to safety of chemicals are worth noting:

\section{Respected Authorities}

Being respected is of paramount importance for enforcement authorities. This has little to do with the number of samples analyzed - an authority works best if it is not even necessary to analyze samples. Commanding respect is mainly related to competence and strict enforcement of really relevant requirements.

Even for a limited field, gaining competence (in depth investigation of the matter and solid analytical methods) takes years, 
which means focusing and temporary specialization. Once a problem is brought up, it must be pursued, even if it takes many more years and various creative methods to succeed. Routine analysis is necessary for some subjects, but it should not predominate.

\section{Open Eyes for Neglected Issues}

Control should not only enforce what legislation spells out in detail, but serve the more general scope of protecting the consumers. It is difficult to size the fields neglected so far, but it was worrying to see how often and easily we encountered them - many more than we could tackle. Not all investigations revealed a real problem, but disturbingly many did. It left the impression that authorities invest nearly all resources into a perhaps small sector and keep themselves so busy that even fairly obvious other problems remain neglected. Since the neglected problems are often far worse than the 'old' ones, a substantial proportion of the resources should be devoted to them.

\section{Getting Problems Solved}

It is naïve to believe that the thorough description of something inacceptable would automatically start a correction process. All too often industry waits to see whether the pressure grows such that really something needs to be done, commonly using formal arguments such that "it is not regulated" (meaning not "specifically regulated"). Competent authorities might write a high standing evaluation of the case, but usually "cannot do anything in this case". Hence the main work only starts at this point.

Mobilizing engagement to solve a problem often needs creativity and unconventional activity. Invitations of colleagues from abroad to analyze their samples in our laboratory were sometimes effective. Collaboration with a willing producer to gain competence and insight into what is really feasible brought us forward several times. Writing scientific papers and lecturing at congresses was usually important to strengthen our position. It may seem awkward that a food control authority analyses human tissues, but it appeared to be a prerequisite to protect the consumers. To avoid that the tax payer had to finance such projects, thesis students paid by university grants were engaged - which in turn presupposed a reputation attracting such researchers.

\section{Communicating the Perception of Chronic Toxicity}

To receive the necessary attention, chronic chemical intoxication requires explanation. It is not like falling dead on the next day, such as by poisons from mush- rooms. Many might believe that they are not affected, even though they are. There is, for instance, evidence that mental problems or obesity can be triggered by chemicals (of course you have to eat much to gain weight, but you may do so because of misguided regulation).

Unless effects are dramatic, chronic intoxication is unlikely to be detected by waiting for complaints, even if millions suffer from it. It is likely to sneak slowly, to weaken certain organs, reduce vitality, render us more susceptible to other health problems or mislead regulation.

Protection against chronic intoxication has to proceed from the other direction: it presupposes drawing up scenarios which then can be investigated. This is tedious work, also as it means investigating many harmless chemicals before a dangerous one is detected.

Politicians calling for further reduction of the resources for control might not have understood the danger, but this might be the fault of authorities in their annual reports stressing their success rather than the large gaps they were unable to narrow. It may also result from routine focusing always on the same and losing sight of the probably far broader neglected field.

\section{Collaboration and Networking}

Enforcement authorities were created to solve local problems, such as watered milk, contamination of drinking water or inadequate hygiene in restaurant kitchens. However, today a large proportion of the foods, process technologies and packaging materials are from international companies and many detected problems (like formation of acrylamide or fatty acid glycidyl esters) are of international relevance.

It may be argued that the tax payer of the canton of Zurich should not be charged to solve problems of international relevance, but there is no structure to cover those. Also in the EU, enforcement is strictly national or even regional. Hence all local authorities should contribute, collaborating to avoid duplication, harmonize evaluation and join to implement measures.

Discussions on finances tend to kill collaboration. They are usually inconclusive, since the benefit cannot be calculated: control performed in Zurich may have its effect for the whole of Europe. It may also, for instance, be more effective to analyze samples from another authority to get the required improvement on the local market. This notwithstanding it is also true that certain countries rely on the control performed by others.

\section{Finding the Best Moment}

Networking is important to enhance the effect of the activities: There is usually a rather narrow time window of enhanced attention for a subject. This is the moment to produce data that fits into a campaign or to launch a concern that can be linked to it. Otherwise a subject has to be carried forward alone, which is a heavy burden as we noticed on several occasions.

\section{Authorities without Measures}

The lid campaigns ${ }^{[38]}$ taught us how little authorities can do in the case of persistent non-compliance by big players: the ultimate measure is removal from the market, but used systematically this would have meant an enormous waste of food and a financial damage in Europe in the order of billions of Euros, primarily hitting the food producers. Authorities lack an effective, though less drastic, more flexible measure directly applicable to the responsible producer even if he is domiciled abroad. Financial fines could be such a one measure if there is no immediate health risk, but should be sized related to the whole European market. Strangely, most European authorities seem not even have noticed their weakness, despite plenty of non-compliance over decades.

The real power seems to be with the media. All too often scandals seem to be a prerequisite for authorities to enact regulations or implement these. This is highly undesirable: the power play between producers and authorities should not be carried out on the back of the consumers and dramatized issues. Most consumers are unable to evaluate risks and are often lost in what they should do. Basically enforcement has the power to implement legal requirements without such help.

\section{Acknowledgment}

I thank all my bosses having supported or at least tolerated unusual activities: Ernst Romann, Reto Battaglia, Martin Brunner, Rolf Etter, Christoph Spinner, Daniel Imhof and Christoph Bürgi. I'm not sure whether another laboratory would have allowed us to go our own way.

I also want to point out that much of our success was due to the committed work of all members of our group, namely (alphabetically) Anna Artho, Maurus Biedermann, Sandra Biedermann-Brem, Marianne Bronz, Anja Fankhauser-Noti, Katell Fiselier, Mauro Lanfranchi, Thomas Läubli, Hans-Peter Neukom, Beat Schilling, Christoph Wagner, Michael Zurfluh and the many interns in our group.

Received: July 7, 2014

[1] K. Grob, H. P. Neukom, J. High Resol. Chromatogr. \& Chromatogr. Commun. 1979, 2 , 15.

[2] K. Grob, LC-GC North America 2008, 26, 1022.

[3] K. Grob, M. De Martin, J. High Resol. Chromatogr. 1992, 15, 399.

[4] K. Grob, M. Biedermann, Anal. Chem. 2002, 74,10 . 
[5] K. Grob, 'Split and splitless injection for quantitative GC', Wiley-VCH, Weinheim, 2001, ISBN 3-527-29879-7.

[6] K. Grob, J. Chromatogr. 1978, 151, 311.

[7] K. Grob, H. P. Neukom, J. Chromatogr. 1980 , 189, 109.

[8] K. Grob, J. Chromatogr. 1981, 213, 3

[9] K. Grob, J. Chromatogr. 1982, 237, 15.

[10] K. Grob, J. Chromatogr. 1983, 279, 225.

[11] K. Grob, J. Chromatogr. 1982, 253, 17.

[12] K. Grob, G. Karrer, M.-L. Riekkola, J. Chromatogr. 1985, 333, 129.

[13] K. Grob, B. Schilling, J. Chromatogr. 1983 $259,37$.

[14] K. Grob, 'On-Column Injection in Capillary GC', Hüthig, Heidelberg, 1987, ISBN 3-77851551-9.

[15] K. Grob, D. Fröhlich, B. Schilling, H.P. Neukom, P. Nägeli, J. Chromatogr. 1984, 295, 55.

[16] K. Grob, 'On-Line Coupled LC-GC', Hüthig, Heidelberg, 1991, ISBN 3-7785-1872-0.

[17] K. Grob, J. Chromatogr. A 2007, 1150, 93.

[18] K. Grob, A. M. Giuffré, U. Leuzzi., B. Mincione, Fat Science Techn. 1994, 96, 286.

[19] K. Grob, M. Biedermann, M. Bronz, C. Mariani, Riv. Ital. Sost. Grasse 1995, 72, 49.

[20] M. Biedermann, K. Grob, C. Mariani, Riv. Ital. Sost. Grasse 1995, 72, 339.

[21] K. Grob, M. Bronz, M. Biedermann, B. Grolimund, U. Boderius, H. P. Neukom, M. Brunner, R. Etter, A. Giuffre, Riv. Ital. Sost Grasse 1995, 72, 525.

[22] K. Grob, M. Biedermann, E. Scherbaum, M. Roth, K. Rieger, Crit. Rev. Food Sci. Nutr. 2006, 46, 529.

[23] S. Biedermann, M. Zurfluh, K. Grob, A. Vedani, B. J. Brüschweiler, Food Chem. Tox. 2013, 58, 107.

[24] M. Biedermann, S. Biedermann-Brem, A. Noti, K. Grob, P. Egli, H. Mändli, Mitt. Lebensm. Hyg. 2002, 93, 638.

[25] A. Noti, S. Biedermann-Brem, M. Biedermann, K. Grob, P. Albisser, P. Realini, Mitt. Lebensm. Hyg. 2003, 94, 167.
[26] T. M. Amrein, S. Bachmann, A. Noti, M. Biedermann, M. Ferraz Barbosa, S Biedermann-Brem, K. Grob, A. Keiser, P. Realini, F. Escher, R. Amadò, J. Agric. Food Chem. 2003, 51, 5556.

[27] K. Grob, J. AOAC Intern. 2005, 88, 253

[28] M. Biedermann, K. Grob, Mitt. Lebensm. Hyg. 2003, 94, 406.

[29] K. Fiselier, F. Gama-Baumgartner, A. Fiscalini, M. Biedermann, K. Grob, D. Imhof, M. Beer, Mitt. Lebensm. Hyg. 2004, 95, 127.

[30] M. Biedermann, F. Grundböck, K. Fiselier, S. Biedermann, C. Bürgi, K. Grob, Food Addit. Contam. 2010, 27, 1352.

[31] C. Ruden, Food Chem. Tox. 2004, 42, 335

[32] FoodDrinkEurope: Acrylamide Toolbox 2013 http://ec.europa.eu/food/food/chemicalsafety/ contaminants/toolbox_acrylamide_201401_ en.pdf

[33] EFSA Update on acrylamide levels in food from monitoring years 2007 to 2010. EFSA Journal 2012, 10, 2938. http://www.efsa.europa.eu/en/ efsajournal/pub/2938.htm

[34] A. Fankhauser-Noti, K. Fiselier, S. BiedermannBrem, M. Biedermann, K. Grob, F. Armellini, K. Rieger, I. Skjevrak, Eur. Food Res. Technol. 2005, 221, 416.

[35] A. Fankhauser-Noti, S. Biedermann-Brem, K. Grob, Eur. Food Res. Technol. 2006, 223, 447.

[36] N. Graubardt, M. Biedermann, K. Fiselier, L. Bolzoni, T. Pedrelli, C. Cavalieri, C. Simoneau, K. Grob, Food Addit. Contam. 2009, 26, 1113.

[37] G. McCombie, A. Harling-Vollmer, M. Morandini, G. Schmäschke, S. Pechstein, W Altkofer, M. Biedermann, S. BiedermannBrem, M. Zurfluh, G. Suter, M. Landis, K. Grob, Eur. Food Res. Technol. 2012, 235, 129.

[38] G. McCombie, A. Harling, M. Biedermann, S. Biedermann-Brem, A. Eicher, G. Suter, M. Morandini, S. Pechstein, G. Schmäschke, U. Lauber, K. Grob, Food Control, 2014, DOI: 10.1016/j.foodcont.2014.08.035.

[39] S. Moret, K. Grob, L. S. Conte, Z. Lebensm. Unters. Forsch. 1997, 204, 241

[40] H.-P. Neukom, K. Grob, M. Biedermann, A Noti, Atmospheric Environment 2002, 36, 4839.
[41] Ch. Droz, K. Grob, Z. Lebensm. Unters. Forsch. 1997, 205, 239.

[42] A. Harling, K. Grob, R. Helling, T. Simat, BMELV, German Federal Ministry of Food, Agriculture and Consumer Protection. Project 2809HS012, 2012. http://download.ble. de/09HS012.pdf

[43] M. Biedermann, J.-E. Ingenhoff, G. Dima, M. Zurfluh, S. Biedermann-Brem, L. Richter, T. Simat, A. Harling, K. Grob, Eur. Food Res. Technol. 2013, 236, 459.

[44] M. Biedermann, K. Grob, J. Chromatogr. A 2012, 1255, 76.

[45] M. Biedermann, K Grob, J. Chromatogr. A 2013, 1293, 107.

[46] S. Biedermann-Brem, K. Grob, Packag. Techn. Sci. 2014, 27, 713.

[47] EFSA, 2012, Scientific Opinion on Mineral Oil Hydrocarbons in Food. EFSA Journal 2012, 10, 2704. http://www.efsa.europa.eu/en/ efsajournal/pub/2704.htm

[48] A. Noti, K. Grob, M. Biedermann, U. Deiss, B. J. Brüschweiler, Reg. Tox. Pharm. 2003, 38, 317.

[49] N. Concin, G. Hofstetter, B. Plattner, C. Tomovski, K. Fiselier, K. Gerritzen, S. Fessler, G. Windbichler, A. Zeimet, H. Ulmer, H. Siegl, K. Rieger, H. Concin, K. Grob, Food Chem. Tox. 2008, 46, 544

[50] K. Grob, J. Stocker, R. Colwell, Food Control 2009, 20, 476; K. Grob, J. Stocker, R. Colwell, Food Control 2009, 20, 483.

[51] K. Grob, G. Marmiroli, Food Control 2009, 20 , 491.

[52] W. Altkofer, B. Brauer, K. Grob, H. Haffke, R. Helling, J. Verbr. Lebensm. 2009, 4, 411; W. Altkofer, B. Brauer, K. Grob, H. Haffke, R. Helling, J. Verbr. Lebensm. 2010, 5, 111.

[53] J. Tillner, K. Grob, Food Addit. Contam. 2014, in press.

[54] K. Grob, Food Control 2014, 46, 312.

[55] N. Arnich, M.-C. Canivenc-Lavier, M. KolfClauw, H. Coffigny, J.-P. Cravedi, K. Grob, A.C. Macherey, D. Masset, R. Maximilien, J.-F. Narbonne, F. Nesslany, J. Stadler, J. Tulliez, Intern. J. Hyg. Env. Health 2011, 214, 271. 